\title{
Finger/Thumb Sucking Habit and Intellectual Functions of Nursery School Children in Mathematical Skills in Rivers State of Nigeria
}

\author{
Amadi-Ali Beatrice Onyebuchi* \\ Department of Early Childhood \& Primary Education Studies, Faculty of Education, Ignatius Ajuru University \\ of Education, Port Harcourt, Rivers State, Nigeria \\ *Corresponding Author: Amadi-Ali Beatrice Onyebuchi, Department of Early Childhood \& Primary \\ Education Studies, Faculty of Education, Ignatius Ajuru University of Education, Port Harcourt, Rivers
}

\begin{abstract}
This paper investigated the extent to which finger(s) or thumb sucking could influence the intellectual functions of nursery three school children in performing mathematical skills of counting 1 to 100; identifying number symbols 1 to 50; doing simple addition, using the number symbols 1 to 9; doing simple subtraction using number symbols 1 to 9; and the ability to recite the days of the week; in Rivers State. The study adopted ex-post facto design. The target population was 7,414 nursery three children who were found in 572 public early childhood care development centres in Rivers State. The sample size was 206 nursery three children (93 digit suckers and 113 non-digit suckers selected from 53 centres, using purposive sampling for digit suckers and simple random sampling technique with picking 'Yes' or 'No' for non-digit suckers. Instrument for data collection was researcher-developed 20 test items titled: "Test for Nursery Three School Children's Intellectual Functions in Mathematical Skills (TNTSCIFMS)”. The instrument was validated by teachers of the sampled children for face and content. A test re-test exercise using the Pearson Product Moment Correlation was used to ascertain the reliability of the instrument which yielded a reliability coefficient ( $r$ ) of 0.70. The instrument was administered by the researcher and class teachers who were used as research assistants. Five research questions and five null hypotheses guided the study. Mean and standard deviation were used to analyze the results of the research questions in tables; while independent t-test was used to analyze the null hypotheses at 0.05 level of significance. The findings of the study revealed among others that digit sucking does not significantly influence the intellectual functions of pre-school children in performing mathematical skills; rather heredity and environment. Based on the findings of the study, it was recommended that parents should not get unnecessarily worried when their children digit suck; rather they should device a peaceful means of making the child stop the habit and preserve their pathological and dental health.
\end{abstract}

Keywords: Digit Sucking, Finger/Thumb Sucking habit, Intellectual Functions, Nursery School Children and Mathematical Skills.

\section{INTRODUCTION}

Since the beginning of human existence, man has always exhibited intellectual functions for the attainment of success in his endeavours. These intellectual functions involved the areas of calculation, problem-solving, ability to give intelligible answers to given questions; as well as the capability of devising means to protect himself from imposing dangers. Adam exhibited a coherent intellectual function in the answer he gave to God concerning why he ate the fruit from the forbidden tree of the knowledge of good and evil (Genesis 3:12). Also, Jochebed, the mother of Moses (Exodus 2:2-4) exhibited a high intellectual function of hiding her son (Moses) for three months from Pharaoh; and when she could no longer hide him, she exhibited the intellectual function of taking an ark of bulrushes, and daubed it with slime and with pitch, and put the child therein; and laid it in the flags by the river's brink; and put the baby's sister to stand afar off, to watch what would be done to him. This her intellectual act gave birth to the popularity of Moses in the old testament of the holy bible.

It was the application of intellectual functions that led the primitive man to the discovery of fire, agriculture, shelter, among others. Family settlement also emerged as a result of intellectual function.

The philosophical and psychological ideas; all the theoretical and scientific perspectives being referenced worldwide today are products of intellectual functions. The mathematical operations and 
the technological advancement widely enjoyed today are also a result of the exhibition of intellectual functions put together and formulated by some individuals. All the above postulations connote that there is no successful human endeavour without the application of intellection function. Therefore, intellectual function could be said to be the ability to process information, reason, remember and proffer solution to any given problem. It is worthy of note though that there is difference in the intellectual functions of individuals (including pre-school children). These differences are contributing factors that determine the ability of the child to properly function intellectually. Among these factors are the chances that intellectually functional parents will likely have intellectually functional children. Intellectually functional parents refer to those parents who in the society possess bachelor degree, degree of masters, Ph.D and professors. This indicates that children's intellectual abilities or functions have strong links with heredity, which sets the potential limits of intellectual capacity. The environment; the nature of play things which the child uses; the kinds of books in the child's home and school; the type of teachers or care-givers that guide the child; the instructional methods and materials employed in teaching the child, the sex (gender) and the age of the child, could account for his intellectual functions.

Montessori as cited in Okon (2004) emphasizing on the strength of the environment and learning materials on the child's development, designed a school environment and apparatus that stressed sensory experience and physical activity with learning materials of various types. These were materials devised to fall in with the child's developing intelligence and skills. Piaget and Pestallozzi also emphasized the importance of a child's environment. In conformity with the views of Montessori, Piaget and Pestallozzi, Vygotsky postulated that a child's learning of new cognitive skills is guided by an adult (or a more skilled child, such as an older sibling), who models and structures the child's learning experience; a process Jerome Bruner later called 'Scaffolding'. According to Vygotsky, as the child becomes more skilled, the zone of proximal development (ZPD) steadily widens, including ever harder tasks (Bee \& Boyd, 2009). Furthermore, interested in the study of the process of human cognitive (intellectual) development, Piaget concluded that intelligence emerges from a child's sensory experience with concrete objects which he can act upon. Piaget designed four stages of cognitive (intellectual) development, namely, sensori motor stage (0-2yrs); pre-operational stage (2-7yrs); concrete operational (7-12yrs); and formal operational stage (12yrs+) (Sokari, 2008).

The four stages through which children's thinking passes through according to Piaget were designed based on the fact that he believed that the process of mental development was hierchical and linked to age. Piaget maintains that intelligence is rooted in two biological attributes found in all living creatures, which are organization and adaptation.

Judging from Piaget's cognitive age identification and distribution, the pre-school child falls into the pre-operational stage. Having mentioned some of the factors that could determine the intellectual functions of the child, it becomes necessary to investigate if finger/thumb sucking habit could possibly influence the intellectual function of the pre-school child.

Finger/thumb sucking habit refers to the insertion of one or two fingers or the thumb into the mouth, rhythmically repeating sucking contact for a prolonged duration. It can also be accompanied with any piece of skin within reach (such as the navel, and the armpit and it is considered to be soothing and therapeutic for the person (Nasir, 2015). Finger/thumb sucking habit is also called digit sucking. It is a habit among children, especially pre-schoolers, that cuts across ethnic, racial and tribal groups. It is a behaviour found in humans, chimpanzees and other primates (Wikipedia). Finger/thumb sucking habit can equally be a way of soothing stress, anxiety and hunger (for the perpetrator). Sometimes sucking happens when a child is bored, meaning that the sucking is just how to entertain himself (Stricker, Miltenberger, Anderson, Tulloch and Deewer (2012).

At birth, a baby will reflexively suck every object placed on its mouth; this is the sucking reflex responsible for breastfeeding. From the very first time infants engage in nutritive feeding, they learn that the habit cannot only provide valuable nourishment, but also a great deal of pleasure, comfort and warmth. Whether from a mother, a bottle, or pacifier, this behaviour overtime begins to become associated with a very strong self-soothing and pleasurable oral sensation. As the child grows older, and is eventually weaned off the nutritional sucking, he can either develop alternative means for receiving those same feelings of physical and emotional fulfillment, or he can continue experiencing those pleasantly soothing experiences by beginning to suck his thumb or finger(s). This reflex 
disappears at about four (4) months of age. Thumb sucking is not purely an instinctive behaviour and therefore can last much longer. Moreover, ultrasound scans have revealed that thumb-sucking can start before birth, as early as fifteen weeks from conception. Whether this behaviour is voluntary or due to random movements of the foetus in the womb is not conclusively known (Larsson \& Dahlin, 2012).

Finger/thumb sucking generally stops by the age of five years; but some older children can retain the habit. When the habit is retained after the age of five years, it can cause severe dental problems. Finger/thumb sucking habit is sometimes retained into adulthood and may be due to stereotypic movement disorder, another psychiatric disorder, or simply habit continuation (Fam, 2015).

Finger/thumb sucking is capable of causing some dental problems such as alveolar pragmatism, caused by thumb sucking and tongue thrusting. This habit can also cause the maxillary central incisors to tip labially and the mandibilar incisors to lip lingually as the thumb or finger rests on them during the course of sucking. Aside from the damaging physical aspects of finger/thumb sucking habit, there are also additional risks, which unfortunately are present at all ages. These include increased risk of infection from communicable diseases, due to the simple fact that non-sterile thumbs or fingers are covered with infectious agents. Finger/thumb sucking also has many social implications, such as experiencing social difficulties, as often children are taunted by their peers for engaging in what they consider to be an "immature" habit. This taunting often results to the child being rejected by the group or being subjected to ridicule by his peers, which can cause understandable psychological stress (Nasir, 2015).

From verbal discussions with parents of suckers, finger/thumb sucking habit seems to be attributed to heredity. In most cases however digit sucking habit appears to be learned from peer group. Factors such as the length of breastfeeding period, duration of feeding time, feeding upsets, and psychological stress having little or no significance in the development of the habit. Whichever, it is advisable to parents, teachers, care-givers and other adults around the child to take note of when and where sucking occurs and try to divert the child's attention by offering an alternative. Other preventive measures to finger/thumb sucking habit which some parents use are the application of bitterants or piquant substances on their child's hands (although this is not a procedure encouraged by the American Dental Association or the American Association of Pediatric Dentist (Nikolopoulou, 2013).

The researcher had some oral communication with teachers and parents and obtained the following replies:

- Finger(s)/thumb sucking habit among pre-schoolers is not a thing to be worried about (R.I. Didia, personal communication, June 28, 2017).

- A female pre-school care-giver argues that intellectual functions of pre-school children is not singularly influenced by finger(s)/thumb sucking habit. A child could suck his/her finger(s) or thumb and equally perform excellently in mathematical skills. This means that heredity and environment play active roles on the intellectual functions of children (S.N. Amadi, personal communication, June, 29, 2017).

- I am not quite sure, but there is a reason to believe that children who suck their finger(s) or thumb may not pay attention during teaching and learning process, hence, it is possible they will not perform very well in mathematics (M.N. Wokamma, personal communication, July 3, 2017).

- No, Ray my son sucked his fingers when he was a pre-schooler; stopped sucking abruptly and never went back to that habit. Finger sucking did not limit his intelligence. He was intellectually functional in all the subjects, including mathematics. Any one that says a child could not perform mathematical skills simply because he/she sucked fingers or thumb is making a mistake. To be intellectually functional or not is far from finger/thumb sucking habit (M.K. Okibe, personal communication, July 10, 2017).

- Destiny is a thumb sucker, I am her care-giver, whenever serious activities are going on in the class, she inserts her thumb into her mouth and cares less about whatever going on around her (E.O. Wagor, personal communication, July, 12, 2017).

I believe that finger(s)/thumb sucking distracts children from their class work. I say this because I am a head teacher and some of the time I walk to the nursery section I reprimand some finger and thumb suckers by flogging and disgracing them before their peers. Sometimes I make other children call 
them suck-suck. The moment this calling of names comes up, the child in question takes off his/her finger from the mouth and joins others to do whatever they are doing. Some of them try in school subjects, but I believe they would do better if they did not suck their finger(s) or thumb. Based on this personal observation, I conclude that finger(s)/thumb sucking habit has influence on intellectual functions of children (W.C. Wike, personal communication, July 14, 2017).

My experience with Angel makes me believe that a child who is destined to be intellectually functional will be, irrespective of the fact that he or she finger/thumb sucks. Angel's thumb sucking habit troubled me and my husband so much that my husband gave her some razor blade cuts on that thumb; but surprisingly this could not stop Angel's thumb-sucking habit. As Angel sucked, it surprised us that she performed very well at school. Angel stopped sucking her thumb towards the end of her nursery three, a period when we even did not expect her to quit the habit (J.B. Makele, personal communication, July 17, 2017).

Miracle is a pre-schooler in my class, I may say that he is an addicted finger sucker, but this does not stop him from doing his class works. He is consistent in his home work. The moment Miracle gets little chance, he inserts his finger into his mouth. The funny thing is that the finger he sucks is on the left hand, so most of the time, Miracle has his finger in the mouth while doing his class work. I announce to you that Miracle performs well in all the subjects, including mathematical skills (B.N. Ojembe, personal communication, July 17, 2017).

Stephanie my daughter sucked both her thumb and lips when she was a pre-schooler and remained very intelligent in her school subjects. Whenever she engaged in any serious work such as calculations, she sucked both her thumb and lips. Then, I saw this habit as her source of comfort and concentration. I believed the habit gave her strength and courage (M.U. Wona, personal communication, July 17, 2017).

Chimenem is a girl in my class whose thumb sucking habit has troubled me a great deal. I have even invited her parents to discuss her sucking problem with them. During my meeting with them, they also expressed great worry. While others are busy playing or doing other activities, Chimenem sits quietly, isolated and puts her finger into the mouth and sucks. Chimenem cannot write very well; she cannot paint and cannot draw; she cannot solve the simplest mathematics. When she sings some rhymes, Chimenem does not pronounce words correctly because her teeth have been affected by the sucking. Eating is also a problem to Chimenem; instead of eating her food, she sucks her thumb. Judging from my experience with Chimenem, I believe that thumb sucking habit obstructs pre-school children's intellectual functions (A.A James, personal communication, July 18, 2017).

Based on the above personal communications, the conduct of this study becomes imperative in order to determine whether finger/thumb sucking habit influences pre-school children's intellectual functions, precisely in mathematical skills in Rivers State.

\subsection{Statement of the Problem}

Finger/thumb sucking habit is an age long habit. It can be said that it is as old as human existence. In the western world, parents have made efforts to prevent finger/thumb sucking habit by children through the provision pacifers. In most cases, some of these children (the suckers) get angry, throw the pacifer away and go on sucking their fingers or thumb. Experience has also shown that the moment any child engages in finger/thumb sucking, his/her whole attention is placed on the sucking. The child seems not to be interested in other activities going on around him at that time. Even on the road, finger/thumb sucking children are reprimanded; at that moment they take their finger or thumb off their mouth; but after a little while, one finds that same child inserting back his finger or thumb into the mouth, sucking. In the classroom, while teaching/learning is going on, finger or thumb suckers are always found deeply engaged in sucking.

Based on the above backdrops, the researcher poses this question: "Does finger/thumb sucking habit not disrupt the intellectual functions of pre-school pupils?" This is the problem that spurred the conduct of this study which is geared towards examining the influence of finger/thumb sucking habit on intellectual functions of pre-school children in Rivers State.

\subsection{Purpose of the Study}

Generally, the purpose of this study was to investigate the influence of finger/thumb sucking habit on intellectual functions of pre-school children in mathematical skills in Rivers State. 
Specifically, the study sought the following objectives which were to:

1. Determine if pre-school children who suck fingers(s) or thumb differ from those who do not, in their ability to count up to 100.

2. Examine if male pre-school children who suck fingers or thumb and female pre-school children who also suck differ in their intellectual functions in identifying number symbols from 1 to 50 .

3. Find out if pre-school children who suck their fingers or thumb and live in well organized environment (stock with educative learning materials) and pre-school children who live in shabby environments differ in their intellectual functions to do simple addition, using the number symbols 1 to 9 .

4. Explore if pre-school school children who suck their finger(s) or thumb and are from intellectually functional parents differ from those suckers who are not from intellectual functional parents in their ability to do simple subtraction, using the number 1 to 9 .

5. Investigate if pre-school children who suck their fingers or thumb, owing to peer group influence differ from those who sucked from birth in their ability to recite the days of the week.

\subsection{Research Questions}

The following research questions were posed to guide the study:

1. How do pre-school children who suck finger(s) or thumb differ from those who do not, in their intellectual functions to count up to 100 ?

2. What is the difference between the intellectual functions of male pre-school children who suck their finger(s) or thumb and the female pre-school children who suck their finger(s) or thumb in their ability to identify number symbols 1 to 50 ?

3. To what extent do pre-school children who suck their finger(s) or thumb and live in well organized environment (stock with educative learning materials) and those that live in shabby environment differ in their intellectual functions to perform simple addition, using number symbols 1 to 9 ?

4. To what extent do pre-school children who suck their finger(s) or thumb and are from intellectually functional parents differ from those who suck their finger(s) or thumb and, are from non intellectually functional parents in their intellectual functions to perform simple subtraction using number symbols 1 to 9 ?

5. What is the difference between the intellectual functions of pre-school children who suck their finger(s) or thumb, owing to peer group influence and those who suck finger(s) or thumb from birth in their ability to recite the days of the week?

\subsection{Null Hypotheses}

The following null hypotheses were formulated to further guide the study:

Ho: Pre-school children who suck their finger(s) or thumb do not significantly differ from those who do not; in their intellectual functions to count up to 100.

$\mathbf{H O}_{2}$ : There is no significant difference between male pre-school children who suck their finger(s) or thumb and female pre-school children who suck their finger(s) or thumb in their ability to identify number symbols 1 to 50 .

H03: Pre-school children who suck their finger(s) or thumb and live in well organized environments (stock with educative learning materials) do not significantly differ from those from shabby environments in their intellectual functions to perform simple addition, using number symbols 1 to 9 .

H0 H $_{\text {: }}$ Pre-school children who suck their finger(s) or thumb and are from intellectually functional parents do not significantly differ from those who suck their finger(s) or thumb and are from non-intellectually functional parents in their intellectual functions to perform simple subtraction; using number symbols 1 to 9 . 
H0 5 : There is no significant difference between pre-school children who suck their finger(s) or thumb, owing to peer group influence and those who suck their finger(s) or thumb from birth in their ability to recite the days of the week.

\section{Methodology}

\subsection{Research Design}

The ex-post facto design was adopted in this study. The researcher employed this research design because she wanted to compare the intellectual functions of pre-school children who suck finger(s) or thumb and those who do not in their ability to perform mathematical skills. Moreso, the ex-post facto design was adopted in the sense that the dependent and independent variables have already existed and cannot be manipulated by the researcher.

\subsection{Population of the Study}

7,414 nursery three children constituted the population of the study. The 7414 nursery three children were found in the 572 public early childhood care development education centres. It should be noted however that there were no nursery three children in Tai Local Government Area; hence, it could be said that the 7,414 nursery three children were found in 565 centres. There were 3,719 male and 3,695 female nursery three children in Rivers State. (Rivers State Universal Basic Education Board, EMIS School Statistics, 2015/2016).

\subsection{Sample and Sampling Technique}

93 digit suckers and 113 non-suckers, making a total of 206 nursery three children constituted the sample size for the study. The 93 digit suckers represent about $7 \%$ of 1,415 children which were found in 53 ECCDE centres. The 53 centres represent about $10 \%$ of the 572 centres found in Rivers State. The researcher decided not to use $10 \%$ of the 93 suckers because the number would have been very small, hence purposive sampling was employed and the 93 digit suckers were used. Observation and checklists for teachers and parents were used to detect the 93 digit suckers; while, simple random sampling technique was used to select 113 non-digit suckers out of 1,322 nursery three children that remained after taking out the 93 digit suckers. The total population of children from the 53 centres was 1,415 children and they represent $10 \%$ of the total population of nursery three children in Rivers State. To get $10 \%$ of 1,322 , simple random sampling technique with picking 'yes' or 'no' was used to select 113 nursery three children. Therefore, 113 children represent $10 \%$ of 1,322.

Among the digit suckers, 49 were male and 44 were female; male non-suckers were 62 and female non-suckers were 51. Digit suckers (male and female) who come from well organized environments were 71, while those from shabby environments were 22; digit suckers who come from intellectually functional parents were 74 (male and female); while those from non-intellectually functional parents (male and female) were 19; digit suckers (male and female) who sucked from birth were 83; while those who sucked as they started pre-school were 10.

It should be noted that there were valued numbers of children in each centre, as well as varied number of centres in each Local Government Area, hence the percentage counts could not rhyme with the stated number of centres.

\subsection{Instrument for Data Collection}

Instrument for data collection was researcher-developed 20 test items titled: "Test for Nursery Three School Children's Intellectual Functions in Mathematical Skills (TNTSCIFMS)". It was used to test the extent finger(s) or thumb sucking could influence the intellectual functions of nursery school children in mathematical skills. This was adapted from the Stanford-Binet's intelligence scale tests modeled in 1916, and illustrated by Berk (2007).

The instrument was divided into two sections. Section A dealt with the demographic data of the child; while section B dealt with the 20 items test. Items 1 to 4 answered research question one; items 5 to 8 answered research question two; items 9 to 12 answered research question three; items 13 to 16 answered research question four; while items 17 to 20 answered research question five. The instrument was scored child by child, while each question was awarded 5marks. The total score expected of each child was $100 \%$. 
Finger/Thumb Sucking Habit and Intellectual Functions of Nursery School Children in Mathematical Skills in Rivers State of Nigeria

\subsection{Validity of the Instrument}

Copies of the instrument (test items) were given to class teachers of the sampleed children for face and content validation. Their corrections and suggestions were adhered to, which certified the instrument valid for the study.

\subsection{Reliability of the Instrument}

To ascertain the reliability of the instrument, a test re-test exercise was carried out in Bayelsa State, using thirty (30) respondents. The Pearson Product Moment Correlation was used to analyze the data that were generated, to determine the reliability coefficient (r) which was 0.70 . Based on this result, the instrument was considered reliable for the study.

\subsection{Administration of the Instrument}

Before administering the instrument, the researcher obtained permission from the Head teachers of the centres, which granted her access to the class teachers and the children. This enabled the research administer first of all the checklists for class teachers and parents whose answer helped the researcher to get the finger(s)/thumb suckers. A time frame of two days were given to teachers and parents. Luckily, there was a $98 \%$ of retrieval. After the retrieval of the checklist, the researcher visited the centres two days later and administered the 20 test items which were solved by the children. The test items were retrieved on the spot to prevent loss and alteration, and this made it possible for a hundred percent retrieval.

\subsection{Method of Data Analysis}

Mean and standard deviation was used to answer and interpret the research questions; while, the independent t-test was used for the statistical analysis of the null hypotheses at .05 level of significance.

\section{DATA ANALYSIS/Discussion OF FINDINGS}

Research Question One: How do preschool children who digit suck differ from those who do not, in their intellectual functions or ability to count up to 100 ?

Table1. Mean and standard deviation for scores of pre-school children who digit sucked and those who did not, in their intellectual ability to count up to 100

\begin{tabular}{|l|l|l|l|}
\hline Variables & $\mathbf{N}$ & \multicolumn{1}{|c|}{$\mathbf{X}$} & SD \\
\hline Pre-school children who suck finger(s) or thumb & 93 & 67.34 & 7.23 \\
\hline Pre-school children who do not suck finger(s) or thumb & 113 & 68.25 & 7.25 \\
\hline
\end{tabular}

$\mathrm{N}=206$ (group $x=93$ and group $\mathrm{B}=113$ )

Result of data analysis in table 1 indicates that the intellectual ability or functions of digit suckers do not significantly differ from those who do not suck. As it is shown in the above table, in mathematical skills of counting up to 100, digit suckers had a mean score of 67.34 and standard deviation of 7.29, while those who do not suck had a mean score of 68.25 and a standard deviation of 7.25.

Research Question Two: What is the difference between the intellectual functions of male preschool children who digit suck and females who also suck; in their ability to identify number symbols 1 to 50 ?

Table2. mean and standard deviation for scores of male pre-school children who digit sucked and those who did not; in their intellectual functions to identify number symbols 1 to 50

\begin{tabular}{|l|c|c|l|}
\hline Variables & $\mathbf{N}$ & $\overline{\mathbf{X}}$ & $\mathbf{S D}$ \\
\hline Male pre-school children who suck thumb or finger(s) & 49 & 65.32 & 8.03 \\
\hline Female pre-school children who suck finger(s) or thumb & & & \\
\hline
\end{tabular}

$\mathrm{N}=93$ for group $x$ and group $y$

Result of data analysis in respect of research question 2 above in table 2 shows that the intellectual functions of male pre-school children who digit differ from female preschool children who also digit suck, in their intellectual functions to identify number symbols 1 to 50 . At is shown on the table, male 
Finger/Thumb Sucking Habit and Intellectual Functions of Nursery School Children in Mathematical Skills in Rivers State of Nigeria

pre-school children who digit suck had a mean score of 65.32 and a standard deviation of 8.03; while female pre-school children who also such had a mean score of 63.92 and a standard deviation of 7.96.

Research Question Three: To what extent do pre-school children (male and female) who digit suck but live in well organized environments and those who digit suck and live in shabby environments; differ in their intellectual functions to perform simple addition using number symbols 1 to 9 ?

Table3. Mean and standard deviation scores of digit suckers who live in well organized environments and those who also digit sucked and live in shabby environments; in their intellectual ability to perform simple addition using number symbols 1 to 9

\begin{tabular}{|c|c|c|c|}
\hline Variables & $\mathbf{N}$ & $\overline{\mathbf{X}}$ & SD \\
\hline Male and female pre-school digit suckers from well organized environment & 71 & 68.72 & 7.03 \\
\hline & 22 & 49.38 & 5.03 \\
\hline
\end{tabular}

$\mathrm{N}=93$ for group $x$ and group $y$

From table 3 above, the result of data analysis in respect of research question 3 shows that pre-school children (male and female) who digit suck but are from well organized environments differ from preschool children (male and female) who digit suck but are from shabby environments; in their intellectual functions to perform simple addition using number symbols 1 to 9 . Pre-school children (male and female) who digit suck but are from well organized environments had a mean score of 68.72 and a standard deviation of 7.03; while pre-school children (male and female) from shabby environments had a mean score of 49.38 and a standard deviation of 5.03 .

Research Question four: To what extent do pre-school children who digit suck and are from intellectually functional parents differ from those who digit suck and are from non-intellectually functional parents; in their intellectual functions to perform simple subtraction using number symbols 1 to 9 ?

Table4. Mean and standard deviation of scores of pre-school children who digit sucked and are from intellectually functional parents and those who also digit suck and are from non-intellectually functional parents in their ability to perform simple subtraction using number symbols 1 to 9

\begin{tabular}{|l|c|c|l|}
\hline Variables & $\mathbf{N}$ & $\overline{\mathbf{X}}$ & SD \\
\hline Digit suckers (male and female) from intellectually functional parents & 74 & 71.03 & 5.95 \\
\hline Digit suckers (male and female) from non-intellectually functional parents & & & \\
& 19 & 67.24 & 4.29 \\
\hline
\end{tabular}

$\mathrm{N}=93$ for group $x$ and group $y$

From the analysis in table 4 above, the result of research question 4 indicates that pre-school nursery three children who digit suck and are from intellectually functional parents differ in their mean scores from those from non-intellectually functional parents in their intellectual functions to perform simple subtraction, using number symbols 1 to 9 .

This is evident on the fact that those from intellectually functional parents had a mean score of 71.03 and a standard deviation of 5.95, while those from non-intellectually functional parents had a mean score of 67.24 and a standard deviation of 4.29.

Research Question Five: what is the difference between the intellectual functions of pre-school children who digit suck from birth and those who digit suck owing to peer group influence; in their ability to recite the days of the week?

Table5. Mean and standard deviation of scores of pre-school children who digit sucked from birth and those who digit sucked owing to peer group influence; in their intellectual ability to recite the days of the week

\begin{tabular}{|l|c|c|l|}
\hline Variables & $\mathbf{N}$ & $\overline{\mathbf{X}}$ & SD \\
\hline Pre-school children who digit suck from birth & 83 & 65.32 & 8.21 \\
\hline Pre-school children who digit suck owing to peer group influence & 10 & 66.28 & 8.34 \\
\hline
\end{tabular}

$\mathrm{N}=93$ for group $x$ and group $y$

International Journal of Humanities Social Sciences and Education (IJHSSE) 
Finger/Thumb Sucking Habit and Intellectual Functions of Nursery School Children in Mathematical Skills in Rivers State of Nigeria

A study of the result shown in table 5 reveals that the intellectual functions of pre-school children who digit suck from birth differ from those who digit suck owing to peer group influence differ in their ability to recite the days of the weeks.

This conclusion was drawn based on the fact that those who digit suck from birth had a mean score of 65.32 and a standard deviation of 8.21; while those that digit suck owing to peer group influence had a mean score of 66.28 and a standard deviation of 8.43 .

Hypothesis One: Pre-school children who sucked their finger(s) or thumb do not significantly differ from those who did no; in their intellectual functions to count up to 100.

Table6. $t$-test analysis showing the difference in the mean performance of pre-school children who sucked finger(s) or thumb and those who did not; in their intellectual functions to count up to 100.

\begin{tabular}{|l|l|l|l|l|l|l|}
\hline Variables & $\mathbf{N}$ & $\overline{\mathbf{X}}$ & SD & df & t-cal & t-crit \\
\hline Pre-school children who sucked finger(s) or thumb & 93 & 67.34 & 7.23 & & & \multirow{2}{*}{0} \\
\cline { 1 - 4 } Pre-school children who did not suck & 113 & 68.25 & 7.25 & 205 & 0.79 & 1.96 \\
\hline
\end{tabular}

$\mathrm{N}=206 *$ significant $\mathrm{p}<.05$

The data in table 6 shows the t-test analysis for the difference in the performance of pre-school children who sucked finger(s) or thumb and those who did not; in their intellectual functions to count up to 100. The result shows a table calculated value of 0.79 and a critical value of 1.96 at .05 level of significance, and the degree of freedom of 205. Since the table calculated value is less than the critical value of 1.96, the null hypothesis is accepted. This implies that there is no significance difference in the mean performance of finger(s) or thumb suckers and those who did not; in their intellectual functions or ability to count up to 100 .

Hypothesis Two: There is no significant difference between male pre-school children who sucked their finger(s) or thumb and female pre-school children who also sucked; in their ability or intellectual functions to identify number symbols 1 to 50 .

Table7. $t$-test analysis of the difference in the mean performance of male pre-school children who digit sucked and female pre-school children who also digit sucked; in their intellectual functions to identify number symbols 1 to 50

\begin{tabular}{|c|c|c|c|c|c|c|}
\hline Variables & $\mathbf{N}$ & $\overline{\overline{\mathbf{X}}}$ & SD & df & t-cal & t-crit \\
\hline Male pre-school children who sucked finger(s) or thumb & 49 & 65.32 & 8.03 & \multirow[b]{2}{*}{92} & \multirow[b]{2}{*}{0.82} & \multirow[b]{2}{*}{1.96} \\
\hline Female pre-school children who also sucked & 44 & 63.92 & 7.96 & & & \\
\hline
\end{tabular}

$\mathrm{N}=93 *$ significant $\mathrm{p}<.05$

Data in table 7 reveals that the calculated value of 0.84 is less than the critical value of 1.96 at .05 level of significance and 92 degree of freedom. Therefore, the null hypothesis is accepted. This means that there is no significant difference in the mean performance of male pre-school children and female pre-school children who sucked their finger(s) or thumb.

Hypothesis Three: Pre-school children who sucked their finger(s) or thumb and lives in well organized environments (stock with educative learning materials) do not significantly differ from those who sucked and lived in shabby environments; in their intellectual functions to perform simple additions, using number symbols 1 to 9 .

Table8. $t$-test analysis of the difference in the mean performance of pre-school children who digit sucked and lived in well organized environments and those who also digit sucked and lived in shabby environments, in their intellectual functions to perform simple additions, using number symbols 1 to 9

\begin{tabular}{|l|l|c|l|l|l|l|}
\hline Variables & $\mathbf{N}$ & $\overline{\mathbf{X}}$ & $\mathbf{S D}$ & $\mathbf{d f}$ & $\mathbf{t}$-cal & t-crit \\
\hline $\begin{array}{l}\text { Pre-school children who digit sucked and lived in well } \\
\text { organized environments }\end{array}$ & 71 & 68.72 & 7.03 & & & \\
\cline { 1 - 6 } $\begin{array}{l}\text { Pre-school children who digit sucked and lived in shabby } \\
\text { environments }\end{array}$ & 22 & 49.38 & 5.03 & 92 & 14.23 & 1.96 \\
\hline
\end{tabular}

$\mathrm{N}=93 *$ significant $\mathrm{p}>.05$ 
Table 8 indicates that the calculated value of 14.23 is greater than the critical value of 1.96 and $\mathrm{df}$ of 92. Since the calculated value of 14.23 is greater than the critical value of 1.96 , the null hypothesis is rejected; meaning that there is significant difference in the mean performance of digit suckers who lived in well organized environments, and digit suckers who lived in a shabby environments; in their intellectual functions to perform simple addition, using number symbols 1 to 9 .

Hypothesis Four: Pre-school children who sucked their finger(s) or thumb, and are from intellectually functional parents and those who sucked, and are from non-intellectually functional parents do not significantly differ in their intellectual functions to perform simple subtractions, using number symbols 1 to 9 .

Table9. t-test analysis of the mean performance of pre-school children who digit sucked, and are from intellectually functional parents and those who digit sucked and are from non-intellectually functional parents; in their intellectual functions to perform simple subtraction, using number symbols 1 to 9.

\begin{tabular}{|l|l|l|l|l|l|l|}
\hline Variables & $\mathbf{N}$ & $\overline{\mathbf{X}}$ & SD & df & t-cal & t-crit \\
\hline Digit suckers from intellectually functional parents & 74 & 71.03 & 5.95 & & & \\
\cline { 1 - 5 } Digit suckers from non-intellectually functional parents & 19 & 67.24 & 4.29 & 92 & 2.09 & 1.96 \\
\hline
\end{tabular}

$\mathrm{N}=93 *$ significant $\mathrm{p}>.05$

Table 9 above presents the calculated value of 2.09, the critical value of 1.96 and df of 92 . Since the calculated value of 2.09 is greater than the critical value of 1.96, the null hypothesis is accepted. This implies that there is significant difference between the mean performance of digit suckers from intellectually functional parents and those from non-intellectually functional parents; in their intellectual functions to perform simple subtractions, using number symbols 1 to 9 .

Hypothesis Five: There is no significant difference between pre-school children who sucked their finger(s) or thumb from birth and those who sucked, owing to peer group influence; in their intellectual functions to recite the days of the week.

Table10. $t$-test analysis of the mean performance of pre-school children who digit sucked from birth and those who sucked, owing to peer group influence; in their intellectual functions to recite the days of the week

\begin{tabular}{|l|l|l|l|l|l|l|}
\hline Variables & $\mathbf{N}$ & $\overline{\mathbf{X}}$ & SD & df & t-cal & t-crit \\
\hline Pre-school children who digit sucked from birth & 83 & 65.32 & 8.21 & & & \\
\cline { 1 - 5 } Pre-school children who digit sucked owing to peer & 10 & 66.28 & 8.43 & 92 & 0.09 & 1.96 \\
group influence
\end{tabular}

$\mathrm{N}=93 *$ significant $\mathrm{p}>.05$

Table 10 above shows the calculated value of 0.09 , the critical value of 1.96 and the df of 92 . Since the critical value of 0.09 is less than the critical value of 1.96 , the null hypothesis is retained. This entails that there is no significant difference between the intellectual functions of pre-school children who digit sucked from birth and those who digit sucked owing to peer group influence; in their ability to recite the days of the week.

\section{DISCUSSION OF FINDINGS}

\section{Intellectual functions of pre-school children who sucked finger(s) or thumb and those who did not; in counting up to number 100.}

The result emerging from analyzing research question 1 and hypothesis 1 indicates that there is no significant difference in the mean performance of finger(s) or thumb suckers and those who did not; in their intellectual functions or ability to count up to 100 . This result is in consonance with the view of (R.I, Didia, personal communication, June, 29, 2017) who argued that finger or thumb sucking is not an issue of worry, as far as intellectual functions are concerned; rather depends on individual difference.

\section{Intellectual functions of male and female pre-school children who digit sucked (finger-sucked) identify number symbols 1 - $\mathbf{5 0}$}

The result obtained from analyzing research question 2 and hypothesis 2 reveals that there is no significant difference in the mean performance of male pre-school children and female pre-school 
children who sucked their finger(s) or thumb (digit sucked). This result is in conformity with (J.B. Makele, personal communication, July, 2017) who believes that a child who is destined to be intellectually functional will be; irrespective of the fact that he/she digit sucks.

Intellectual functions of pre-school children who digit sucked and lived in well organized environment and those who also digit sucked and lived in shabby environments to perform simple additions, using number symbols 1-9

The result derived from analyzing research question 3 and hypothesis 3 shows that there is significant difference in the intellectual functions of pre-school children who digit sucked and lived in well organized environments and those who digit sucked and lived in shabby environment to perform simple additions, using number symbols $1-9$.

This result is in agreement with (E.N Owabie, personal communication, July, 18, 2017) who revealed that the intellectual function of a child is not dependent on whether he/she sucks finger(s) or thumb, but on the type of home and school environment the child interacts with.

Intellectual functions of pre-school children who digit sucked and are from intellectually functional parents and those who digit sucked and are from non-intellectually functional parents to perform simple subtractions, using number symbols 1 - 9

The result emerging from analyzing research question 4 and hypothesis 4 indicates that there is significant difference between the mean performance of digit suckers from intellectually functional parents and those from non-intellectually functional parents in performing simple subtractions, using number symbols $1-9$.

Intellectual functions of pre-school children who digit sucked from birth and those who digit sucked, owing to peer group influence, to recite the days of the week

The result obtained from analyzing research question 5 and hypothesis 5 reveals that there is no significant difference between the intellectual functions of pre-school children who digit sucked from birth and those who digit sucked owing to peer group influence in their ability to recite the days of the week.

This result agrees with Piaget as cited in Sokari (2008) who concluded that intelligence emerges from a child's sensory experience with concrete objects which he acts upon. It simply means that being a digit sucker from birth or as a result of peer group influence has little or no influence on the child's intellectual ability.

\section{CONCLUSION}

Judging from the findings of the study, the following conclusion was drawn:

- Finger(s) or thumb sucking or digit sucking has no significant influence on the intellectual functions of pre-school children; but individual difference; parental status, heredity and environment do.

\section{Recommendations}

Based on the findings of the study, the following recommendations are made:

1. Pre-school children (whether digit suckers or not) should be treated with love.

2. Digit suckers should be encouraged by parents, care-givers or teachers and other older persons around to stop the habit, bearing in mind the perpetrator's pathological and dental health.

3. The environment (home and school) of the child (digit suckers inclusive) should be well organized and conducive for learning new experiences.

\section{REFERENCES}

[1] Bee, H. and Boyd, D. (2009). The developing child (11 $1^{\text {th }}$ edition). New York: Pearson Education Inc. p. 257.

[2] Berk, I.E. (2007). Child development ( $6^{\text {th }}$ edition). New Delhi: Daling Kindersley Limited. P. 186.

[3] EMIS School Statistics (2015/2016). ECEDE school enrolment by gender by class. Port Harcourt: Rivers State Universal Basic Education Board. 
[4] Fam, A.M. (2015). Thumb sucking and pacifer use. A out on early childhood issues, 15; 92(4); $274-278$.

[5] Gideons International: The holy bible (the authorized King James version, Revised 2016). Boltext. National publishing company.

[6] Larsson, E. and Dahlin, K.G. (2012). The prevalence and the actiology of the initial dummy and finger sucking habit. American Journal of Orthodontics 87(8): 435-437.

[7] Nasir, L.M.D. (2015). Counselling on early childhood concerns. Sleep issues, thumb-sucking, picky eating, school readiness, and oral health. Omaha, Nebraska: Creighton University School of Medicine.

[8] Nikolopoulou, M. (2013). Preventing digit sucking problems in infants. Arch Dis Child, 88(2): 108-111.

[9] Okon (2004). Early childhood education: Concept and scope, in Q.I. Obinaju (ed.). Early childhood education: Theory and practice ( $2^{\text {nd }}$ edition). Calabar: BON Universal Limited, pp. 9-11.

[10] Sokari, H.S. (2008). Philosophical basis of primary education ( $2^{\text {nd }}$ edition), in C.O. Iwundu (ed.). perspectives in basic education. Port Harcourt: Rodi printing and publishing company, pp. 41-42.

[11] Stricker, J.M Miltenberger, R., Anderson, C., Tulloch, H. \& Deaver, C. (2012). A functional analysis of finger sucking in children. Behaviour modification, 26(3), 424-443.

[12] Wikipedia - thumb sucking. Retrieved from http://enwikipedia.org/wiki/Thumbsucking.

Citation: Amadi-Ali Beatrice Onyebuchi. " Finger/Thumb Sucking Habit and Intellectual Functions of Nursery School Children in Mathematical Skills in Rivers State of Nigeria "International Journal of Humanities Social Sciences and Education (IJHSSE), vol 7, no. 6, 2020, pp. 156-167. doi: http://dx.doi.org/10.20431/2349-0381.0706017.

Copyright: (C) 2020 Authors. This is an open-access article distributed under the terms of the Creative Commons Attribution License, which permits unrestricted use, distribution, and reproduction in any medium, provided the original author and source are credited. 